\title{
The Semitransparent Photovoltaic Films for Mediterranean Greenhouse: A New Sustainable Technology
}

\author{
Alvaro Marucci, ${ }^{1}$ Danilo Monarca, ${ }^{1}$ Massimo Cecchini, ${ }^{1}$ \\ Andrea Colantoni, ${ }^{1}$ Alberto Manzo, ${ }^{2}$ and Andrea Cappuccini ${ }^{1}$ \\ ${ }^{1}$ Department of Agriculture, Forests, Nature and Energy (DAFNE), University of Tuscia, 01100 Viterbo, \\ Italy \\ ${ }^{2}$ SACO VI Office-Nursery Gardening, Ministry of Agricultural, Food and Forestry Policies (IMAFFP), \\ Via XX Settembre, 20, 00187 Rome, Italy
}

Correspondence should be addressed to Alvaro Marucci, marucci@unitus.it

Received 16 October 2012; Accepted 8 November 2012

Academic Editor: Massimo Scalia

Copyright (C) 2012 Alvaro Marucci et al. This is an open access article distributed under the Creative Commons Attribution License, which permits unrestricted use, distribution, and reproduction in any medium, provided the original work is properly cited.

\begin{abstract}
Mediterranean countries offer very favorable climatic conditions for growing plants in a protected environment: as a matter of fact, the high solar radiation allows the use of greenhouses with simple structures, covered with plastic film and without fixed installations for winter heating. They are called "Mediterranean greenhouses" and are totally different from those in Central and Northern Europe. In the photovoltaic greenhouses, the cover on the pitch facing south is usually replaced by very opaque panels. However, this solution compromises the possibility to grow plants in covered and protected environments since solar radiation availability is limited and strongly nonuniform. In order to overcome this problem, semitransparent photovoltaic materials can be used to let the solar energy, necessary for plant growth, pass into the green house. The aim of this research is to analyze the radiometric properties of innovative semitransparent flexible photovoltaic materials in order to evaluate their performances in comparison with materials commonly used in the coverage of the greenhouses. Particular attention is paid to the transmittance of these materials in the visible range and in the long wave infrared for the achievement of greenhouse effect.
\end{abstract}

\section{Introduction}

Recently, the use of greenhouse surface has increasingly spread worldwide.

Spain is in the first place in Europe with 50,000 hectares; there are 60,000 hectares in Japan and in China it is estimated that from 350,000 to 700,000 hectares are destined to protected crops. The phenomenon is developing not only in countries with temperate climate, 
but also in tropical and subtropical areas in Latin America, Africa, Asia, and around the Mediterranean basin.

In Europe, greenhouse design and construction are governed by the Standard EN 13031-1:2001 where the following definition is given: "Greenhouse is structure used for the cultivation and/or protection of plants and crops that exploits the transmission of solar radiation under controlled conditions to improve the environment of growth, with dimensions that allow people to work inside."

The greenhouse can be seen as a solar collector which exploits the radiation coming from the sun to create optimal conditions for plant growth and development.

The solar radiation inside the greenhouse depends on

(i) incident radiation on the ground;

(ii) shape and orientation of the greenhouse;

(iii) type of structure;

(v) transmittance, absorption, and reflection of the covering material;

(vi) size and position of the opaque structure;

(vii) dust on the cover;

(viii) cover condensation.

Covering material is the most important feature among the above-mentioned parameters since its own characteristics influence the microclimate in the confined environment.

Greenhouse cover, structural elements, soil, and crop contribute to the solar radiation absorption, and consequently, to the generation of sensible or latent heat [1].

Glass, semirigid plastics and plastic films are the most widely used greenhouse covering materials. They protect crop from adverse weather conditions and influence the greenhouse microclimate modifying the growing conditions of crops in comparison with the open-field climatic conditions.

Covering materials modify greenhouse microclimate due to their transmissivity to solar radiation in the visible range and in the long infrared radiation.

The spectral distribution of solar radiation at the earth's surface must be taken into account as a weighting function to calculate radiometric coefficients of covering materials. About $50 \%$ of the total energy is emitted in the near infrared radiation (NIR) range (700$2,500[\mathrm{~nm}])$ and nearly $40 \%$ in the PAR range (400-700 [nm]), where the solar radiation has a maximum at a wavelength of approximately 500 [nm] [2].

The transmissivity coefficient in the solar wavelength range, from $300[\mathrm{~nm}]$ to $2,500[\mathrm{~nm}]$, represents the fraction of the overall solar radiation passing through the covering material. The transmissivity coefficient in the PAR range expresses the quantity of solar PAR radiation transmitted by the covering material and strongly influences crop growth and yield.

Long wave infrared radiation energy losses from protected environments depend on the transmissivity of the covering material in the wavelength values higher than 3000 [nm]. However, at ambient temperature the bodies have the maximum energy emission in the range 7,500-12,500 [nm] [3].

The air temperature inside greenhouse is significantly influenced by the emissivity of the covering material which is a measure of the thermal radiative energy emitted in the long infrared radiation: if the covering material has high emissivity, high energy losses occur from the protected environment. 
Table 1: Transmissivity coefficients of different greenhouse covering materials.

\begin{tabular}{lcccc}
\hline Transmissivity coefficients, $\%$ & Glass & LDPE & EVA & ETFE \\
& $4 \mathrm{~mm}$ & $0.180 \mathrm{~mm}$ & $0.180 \mathrm{~mm}$ & $0.100 \mathrm{~mm}$ \\
\hline$\tau_{\text {SR }}$ & 80.4 & 88.6 & 89.1 & 93.1 \\
$\tau_{\text {PAR }}$ & 87.5 & 91.0 & 89.7 & 92.4 \\
$\tau_{\text {LWIR }}$ & 0.00 & 53.7 & 25.9 & 10.9 \\
\hline
\end{tabular}

SR: solar radiation; PAR: photosynthetically active radiation; LWIR: long wave infrared [4].

Thus, the radiometric properties of the greenhouse cover play an important role in reducing energy consumption [4]. Sustainability of greenhouse industry can be increased with innovative covering materials aimed at obtaining energy savings in greenhouse heating and cooling together with profitable yield. Moreover, covering materials-able to modify the spectral distribution of the solar radiation - can be used to influence plant growth in place of agrochemicals. In the latest decades research has been addressed to improve the radiometric properties of glasses and, more recently, of plastic films that are the most widespread greenhouse covering materials [4].

Plastic films are very different from glass, are characterized by low cost, and require a lighter support frame. Furthermore, they have good thermooptical and mechanical properties, good chemical resistance, and considerable opposition to microbial degradation.

In the last decades of the past century different kinds of plastic films for greenhouses were made by different raw materials and additives.

(i) LDPE (low-density polyethylene) is the most used covering material and has good mechanical and radiometric properties. In the wavelength range 200-2,500 [nm] the total transmissivity of the LDPE film is similar to that of glass. On the other hand, the LDPE has high value of the transmissivity in the long wave infrared radiation.

(ii) EVA (Ethylene vinyl acetate) is the copolymer of ethylene and vinyl acetate, is characterized by lower transmissivity in long wave infrared radiation, and allows to reduce the thermal infrared losses.

(iii) ETFE (ethylene-tetrafluoroethylene copolymers): these innovative recently developed films are characterized by very good radiometric properties (high transmissivity in the solar range and low transmissivity in the long wave infrared radiation). ETFE films costs are higher than LDPE and EVA films but they last longer (also 15 years).

Table 1 shows the values of average transmittance of the covering materials for the above-described greenhouse. While transmittance of plastic films is nearly $10 \%$ higher than that of glass, the infrared transmittance of the LDPE exceeds 50\% with negative consequences on greenhouse effect, EVA is strongly better reaching about $25 \%$ and ETFE is close to $10 \%$. There are few differences of transmittance of the materials considered in the PAR.

Energy production from renewable sources, the diversification of the productive activities, and the development of photovoltaic technology and integrated systems have led to the development of solar greenhouses [5].

Currently, the research is directed to the creation of semi-transparent photovoltaic films. This need stems from the following fact: in some periods of the year, Mediterranean areas are characterised by strong surplus of solar radiation if compared with needs. As a consequence, passive (such as shading nets and thermal shields) or dynamic (natural or 
forced ventilation, spraying or evaporation of water, etc.) protections are required; otherwise suspending farming becomes mandatory.

This has led to exploit the surplus of solar energy to produce electricity to be used in different ways, for example, for cooling systems and/or for direct sale to the distribution companies, and so forth.

A significant problem has to be considered: the traditional photovoltaic silicon-based panels are not transparent and do not let the solar radiation penetrate inside the greenhouse. Thus, plants, cultivation becomes problematic and it is difficult to create greenhouse effect necessary to develop the microclimatic conditions for crops.

In order to solve this problem, researchers are developing panels with partially transparent materials in flexible sheets or semitransparent rigid panels that allow the passage of sunlight necessary for the plants, cultivation in protected environments.

A research has been carried out in an area with a strong vocation for greenhouse crops, that is, the Agro Pontino, in order to obtain useful information on the possibility of using the structures of the greenhouses-meant for horticultural production-to support semitransparent photovoltaic covers. This research has tried to identify available solar energy surplus for its conversion into electrical energy and simultaneously satisfying the needs of the crop in terms of solar energy.

It was found that within the greenhouse-not only in summer, but also in other periods of the year-excess solar energy obliges the farmer to control the internal microclimate systems to prevent damage to the crops. Such systems often become burdensome and complex since high solar radiation is related to high values of air temperature. These excesses could then be used to produce electricity by photovoltaic cells with the advantage of producing energy and saving up for cooling in the protected area.

The research showed that the foot, outside the greenhouse, with cultivations (eggplant) can reach peak daily average of about $15 \mathrm{MJ} \mathrm{m}^{-2} \mathrm{~d}^{-1}$. These peaks remain almost constant in clear sky days during summer.

On cloudy days, of course, these peaks undergo a sharp drop down to about $5 \mathrm{MJ} \mathrm{m}^{-2} \mathrm{~d}^{-1}$, only for the summer months and in the absence of crops.

Moreover, during the months of April and October, a modest surplus occurs (about $2.5 \mathrm{MJ} \mathrm{m}^{-2} \mathrm{~d}^{-1}$ ) at the transplant eggplant (two cycles per year). Taking into account that the surveyed area can be considered clear more than $70 \%$ of the days during summer, solar energy is available for a bit more than 4 months per year and can be transformed using photovoltaic technology.

Once magnitude and temporal distribution of energy surplus are defined; photovoltaic roofs have to be identified. Rigid and opaque panels (the well-known and common silicon solar panels) are not recommended. The solution may be found in the use of flexible photovoltaic and semi-transparent sheets. These being flexible have the ability to be rolled up and, therefore, could be stretched during periods of surplus of the day quite easily as if they were shading nets.

These semitransparent sheets must ensure that the inside of the greenhouse reaches a rate of solar radiation necessary for plants and to create the greenhouse effect. In this way it will be possible to combine the use of the greenhouse for agricultural production and the production of electricity by means of photovoltaic cells.

In order to achieve this goal, the radiometric characterization of these new semitransparent photovoltaic films is needed.

In spectral analysis some wavelengths result more important than others. Variations of blue (B, 400-500 [nm]), red (R, 650-670 [nm]), and far-red (FR, 720-740 [nm]) radiation, 
in the protected environment affect the plant photomorphogenesis. Infact, the phytochrome response is characterized in terms of the R/FR ratio [6-11].

Significant increases of the growth and of the elongation of shoots were pointed out in peach and cherry trees grown under a photoselective film that reduced the R/FR ratio to 0.93, from the value 1.15, which was recorded in open field at the University of Bari [4].

Tests carried out on ornamental plants showed that the increase of the R/FR ratio has a dwarfing effect on the plant growth [9].

The purpose of this work is to characterize the semitransparent photovoltaic flexible film innovative from a radiometric point of view.

\section{Preliminary Remarks}

\subsection{Solar Radiation}

The sun emits as a black body at $5700\left[{ }^{\circ} \mathrm{K}\right]$. According to the Wien's law, the maximum of the emission is at a wavelength $\lambda$ :

$$
\lambda_{\max }=\frac{2885000}{T}=506[\mathrm{~nm}]
$$

The spectrum of solar radiation is between 290 and 3000 [nm]: ultraviolet (290-380 [nm]), visible (380-760 [nm]), and near wave infrared (760-3000 [nm]).

The incident radiation on the ground, with clear skies, can be calculated with the following relations:

$$
\begin{aligned}
& R_{b}=\text { direct radiation at ground }=R_{e} \tau_{b} \cos \theta_{Z}\left[\mathrm{~W} \mathrm{~m}^{-2}\right] \\
& R_{d}=\text { diffuse radiation at ground }=R_{e} \tau_{d} \cos \theta_{Z}\left[\mathrm{~W} \mathrm{~m}^{-2}\right] \\
& R_{g}=\text { global radiation at ground }=R_{b}+R_{d}\left[\mathrm{~W} \mathrm{~m}^{-2}\right] ;
\end{aligned}
$$

where

$$
\begin{aligned}
& R_{e}=\text { outer radiation }=1367(1+0.033 \cos (360 / 365 n))\left[\mathrm{W} \mathrm{m}^{-2}\right] \\
& n=\text { Julian day; } \\
& \cos \theta_{Z}=\operatorname{cosine} \text { zenith angle }=\operatorname{sen} \phi \sin \delta+\cos \phi \cos \delta \cos \omega ; \\
& \phi=\text { local latitude }\left[^{\circ}\right] ; \\
& \delta=\text { Inclination of the sun }=23.45 \operatorname{sen}[(360 / 365)(284+n)]\left[^{\circ}\right] \\
& \omega=\text { hour angle }=(360 / 24)(12-h)\left[^{\circ}\right] \\
& h=\text { hour days }[\mathrm{h}] \\
& A=\text { altitude }[\mathrm{km}] \\
& \tau_{b}=\text { transmissivity of the atmosphere to the direct radiation }=A_{\mathrm{o}}+A_{1} \times e^{-k / \cos \theta_{z}} ; \\
& \tau_{d}=\text { transmissivity of the atmosphere to the diffuse radiation }=0.271-0.294 \tau_{b} ; \\
& A_{0}=\left[0.4237-0.00821(6-A)^{2}\right][1+0.03 \operatorname{sen}(\pi((91+n) / 182))] \\
& A_{1}=\left[0.5055+0.00595(6.5-A)^{2}\right][1+0.01 \operatorname{sen}(\pi((91+n) / 182))] \\
& K=\left[0.2711+0.01858(2.5-A)^{2}\right][1.01-0.01 \operatorname{sen}(\pi((91+n) / 182))]
\end{aligned}
$$


If the surface is inclined, there will be two angles:

$Z=$ inclination of the surface normal with respect to zenith;

$\psi=$ angle between the horizontal projection of the surface normal and the south.

The angle between the direction of the sun and the normal surface is

$$
\begin{aligned}
\cos I= & \operatorname{sen} \lambda \operatorname{sen} \delta \cos Z-\cos \lambda \operatorname{sen} \delta \operatorname{sen} Z \cos \psi+\cos \lambda \cos \delta \cos \omega \cos Z \\
& +\operatorname{sen} \lambda \cos \delta \cos \omega \operatorname{sen} Z \cos \psi+\cos \delta \operatorname{sen} \omega \operatorname{sen} Z \operatorname{sen} \psi
\end{aligned}
$$

The components of radiation are

$$
\begin{aligned}
& R_{b I}=\text { direct radiation on inclined surface }=R_{e} \tau_{b} \cos I ; \\
& R_{d I}=\text { diffuse radiation on inclined surface }=R_{e} \tau_{d} \cos I .
\end{aligned}
$$

The solar radiation that enters the greenhouse is obtained from the previous considering the transmittance of the covering material which varies with the angle of incidence.

In order to calculate this parameter, the following model can be considered.

\subsection{Transmittance of the Cover}

$S$ is the thickness of the cover, $n$ the refractive index, and $k$ the coefficient of absorption.

$$
\text { By the relation: } \frac{n_{1}}{n_{2}}=\frac{\operatorname{sen} \theta_{r}}{\operatorname{sen} \theta_{i}}
$$

being the refractive index of air close to 1 , with $n_{2}=n$ (refractive index of the second), it has

$$
\begin{aligned}
& \qquad \theta_{r}=\text { refraction angle }=\operatorname{arcsen}\left(\frac{\operatorname{sen} \theta_{i}}{n}\right), \\
& \text { Surface reflectance (normal component) }=r_{\perp}=\frac{\operatorname{sen}^{2}\left(\theta_{r}-\theta_{i}\right)}{\operatorname{sen}^{2}\left(\theta_{r}+\theta_{i}\right)}, \\
& \text { Surface reflectance (parallel component) }=r_{\|}=\frac{\tan ^{2}\left(\theta_{r}-\theta_{i}\right)}{\tan ^{2}\left(\theta_{r}+\theta_{i}\right)}, \\
& \text { Total surface reflectance }=r=\frac{I_{r}}{I_{i}}=\frac{1}{2}\left(r_{\perp}+r_{\|}\right) .
\end{aligned}
$$

The transmittance value of the perpendicular component considering the only loss by reflection is

$$
\tau_{\perp}=\left(1-r_{\perp}\right)^{2} \sum_{n=0}^{\infty} r_{\perp}^{2 n}=\frac{\left(1-r_{\perp}\right)^{2}}{\left(1-r_{\perp}^{2}\right)}=\frac{1-r_{\perp}}{1+r_{\perp}}
$$


Similarly, the parallel component of transmittance, considering only losses by reflection, will be

$$
\tau_{\|}=\frac{1-r_{\|}}{1+r_{\|}}
$$

Global transmittance considering only losses by reflection is

$$
\tau_{r}=\frac{1}{2}\left[\frac{1-r_{\perp}}{1+r_{\perp}}+\frac{1-r_{\|}}{1+r_{\|}}\right]
$$

Global transmittance considering only losses by absorption is

$$
\tau_{a}=e^{-K \cdot s / \cos \theta_{r}}
$$

The transmittance, reflectance, and absorbance of a single covering, considering the losses by reflection and absorption, can be determined:

$$
\tau_{\|}=\frac{\tau_{a}\left(1-r_{\|}\right)^{2}}{1-\left(r_{\|} \tau_{a}\right)^{2}}=\tau_{a} \cdot \frac{1-r_{\|}}{1+r_{\|}} \cdot \frac{1-r_{\|}^{2}}{1-\left(r_{\|} \tau_{a}\right)^{2}} \cong \tau_{a} \cdot \frac{1-r_{\|}}{1+r_{\|}}
$$

Similarly,

$$
\tau_{\perp} \cong \tau_{a} \cdot \frac{1-r_{\perp}}{1+r_{\perp}}
$$

Whence,

$$
\begin{gathered}
\tau=\frac{1}{2}\left(\tau_{\|}+\tau_{\perp}\right) \cong \frac{1}{2}\left(\tau_{a} \cdot \frac{1-r_{\|}}{1+r_{\|}}+\tau_{a} \cdot \frac{1-r_{\perp}}{1+r_{\perp}}\right), \\
\tau \cong \tau_{a} \cdot \frac{1}{2}\left(\frac{1-r_{\|}}{1+r_{\|}}+\frac{1-r_{\perp}}{1+r_{\perp}}\right) \cong \tau_{a} \cdot \tau_{r} .
\end{gathered}
$$

Therefore, the global transmittance considering both the absorption losses both the reflection losses is equal to

$$
\tau \cong \tau_{a} \cdot \tau_{r} .
$$

The reflectance of the cover will be

$$
\rho_{\|}=r_{\|}+\frac{\left(1-r_{\|}\right)^{2} \tau_{a}^{2} r_{\|}}{1-\left(r_{\|} \tau_{a}\right)^{2}}=r_{\|}\left(1+\tau_{a} \tau_{\|}\right) .
$$


Similarly,

$$
\rho_{\perp}=r_{\perp}\left(1+\tau_{a} \tau_{\perp}\right) .
$$

Whence,

$$
\rho=\frac{1}{2}\left(\rho_{\|}+\rho_{\perp}\right) .
$$

The absorbance is

$$
\alpha_{\|}=\left(1-\tau_{a}\right)\left(\frac{1-r_{\|}}{1-r_{\|} \tau_{a}}\right) .
$$

Similarly,

$$
\alpha_{\perp}=\left(1-\tau_{a}\right)\left(\frac{1-r_{\perp}}{1-r_{\perp} \tau_{a}}\right)
$$

Whence,

$$
\alpha=\frac{1}{2}\left(\alpha_{\|}+\alpha_{\perp}\right) .
$$

The transmittance of the diffuse radiation is assumed to be equal to the transmittance to direct radiation with $I=60^{\circ}$.

\subsection{Energy Flows in Mediterranean Greenhouse (Tunnel)}

The energy balance equation per unit area for Mediterranean greenhouse (tunnel) is (Figure 1)

$$
R_{i}+R_{\mathrm{ac}}=R T_{g, \mathrm{sky}}+R T_{g, \mathrm{~atm}}+R T_{p, \mathrm{sky}}+R T_{p, \mathrm{~atm}}+R T_{c, \mathrm{sky}}+R T_{c, \mathrm{~atm}}+T_{c}+V+\Delta E_{g}+S_{g}
$$

where

$$
T=K S\left(T_{i}-T_{e}\right)
$$

$K$ is the thermal transmittance $\left[\mathrm{W} \mathrm{m}^{-2} \mathrm{~K}^{-1}\right] ; S$ is the wall surface $\left[\mathrm{m}^{2}\right] ; T_{i}$ is the internal temperature $\left[{ }^{\circ} \mathrm{C}\right] ; T_{e}$ is the external temperature $\left[{ }^{\circ} \mathrm{C}\right]$;

$$
E_{v}=V\left(H_{i}-H_{e}\right)
$$

$E_{v}$ is the energy lost for ventilation $\left[\mathrm{KJ} \mathrm{h}^{-1}\right] ; V$ is the flow rate of ventilation [KgDryAir h$\left.{ }^{-1}\right]$; $H_{i}$ is the internal air enthalpy [KJ KgDryAir $\left.{ }^{-1}\right] ; H_{e}$ is the external air enthalpy [KJ KgDryAir ${ }^{-1}$ ]. 


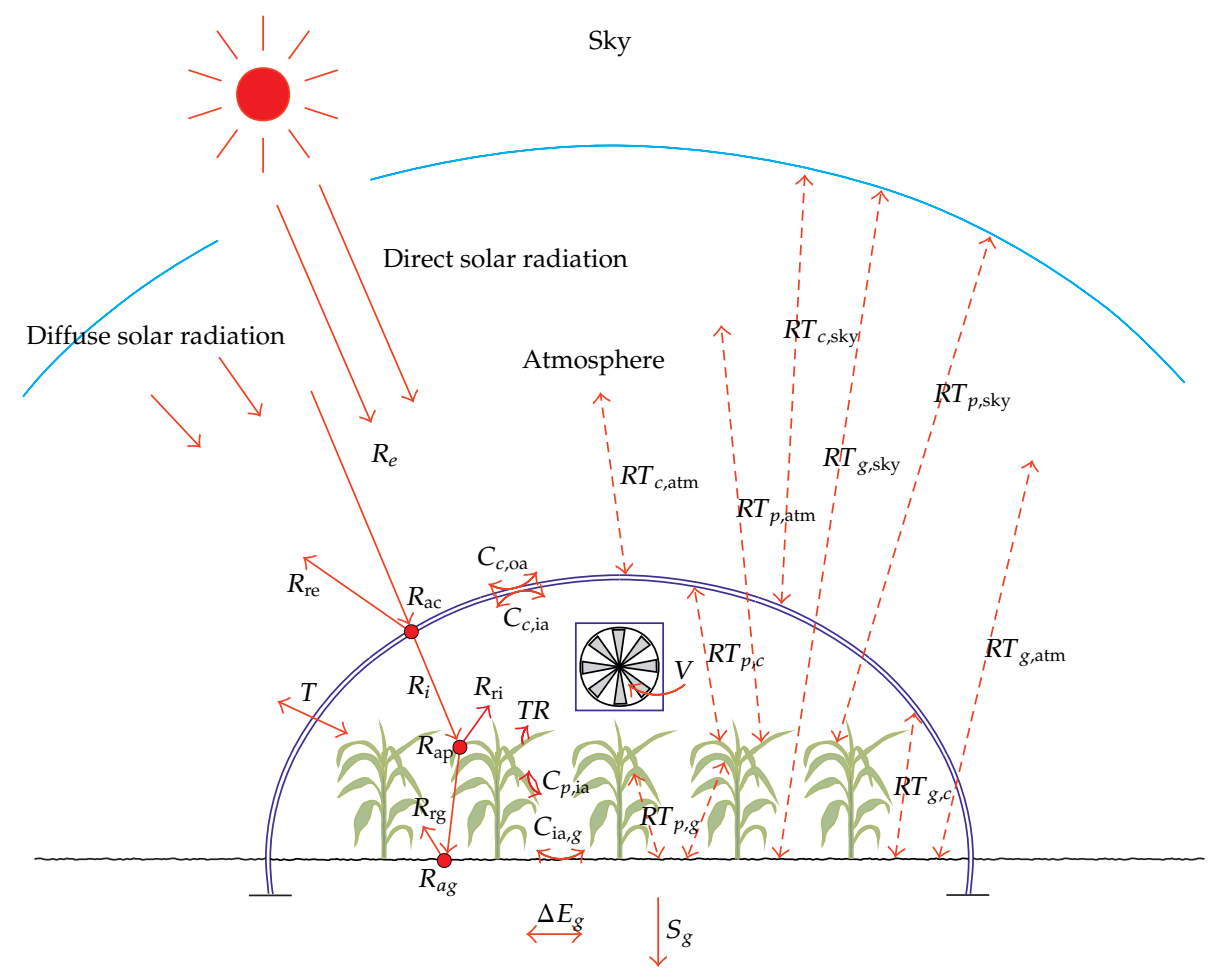

Figure 1: Energy flows in Mediterranean greenhouse.

The enthalpy $H\left[\mathrm{KJ} \mathrm{KgDryAir}{ }^{-1}\right]$ of a $\mathrm{Kg}$ of air, at temperature $t\left[{ }^{\circ} \mathrm{C}\right]$ and with a water content, in the form of water, equal to $x\left[\mathrm{Kg} \mathrm{KgDryAir}^{-1}\right]$ is obtained from

$$
H=1.005 t+x(2499.5+2.005 t),
$$

where $x\left[\mathrm{Kg} \mathrm{KgDryAir}^{-1}\right]$ represents the water vapor contained in the air and can be determined through the psychrometric diagram or by the following formula:

$$
x=0.6215 \frac{p_{\mathrm{H}_{2} \mathrm{O}}}{p-p_{\mathrm{H}_{2} \mathrm{O}}}
$$

where $p=1.013\left[\mathrm{Kg} \mathrm{cm}^{-2}\right]$ is the atmospheric pressure; $p_{\mathrm{H}_{2} \mathrm{O}}$ is the vapor pressure of the air, expressed in $\mathrm{Kg} \mathrm{cm}^{-2}$ at the temperature $T$ [ ${ }^{\circ} \mathrm{K}$ ] and at relative humidity UR [\%];

$$
\begin{aligned}
& p_{\mathrm{H}_{2} \mathrm{O}}=1.41 \times 10^{10} e^{(-3928.5 /(T-41.5))} \times \mathrm{UR}[\mathrm{Pa}] \\
& \mathrm{RT}_{12}=\sum_{\lambda=2.5 \mu \mathrm{m}}^{\lambda=20 \mu \mathrm{m}} \varepsilon_{12}(\lambda) \times \tau_{a}(\lambda) \times \frac{C_{1}}{\lambda^{5}} \times\left[\frac{1}{e^{\mathrm{C}_{2} /\left(\lambda \times T_{1}\right)}-1}-\frac{1}{e^{\mathrm{C}_{2} /\left(\lambda \times T_{2}\right)}-1}\right] \times \Delta \lambda ;
\end{aligned}
$$

$\mathrm{RT}_{12}$ is the radiated radiation $\left[\mathrm{W} \mathrm{m}^{-2}\right] ; \lambda$ is the wavelength $[\mu \mathrm{m}] ; T$ is the absolute temperature $\left[{ }^{\circ} \mathrm{K}\right] ; C_{1}=3.7410^{8}\left[\mathrm{~W} \mu \mathrm{m}^{4} \mathrm{~m}^{-2}\right] ; C_{2}=14385[\mathrm{~K} \cdot \mu \mathrm{m}] . \tau_{a(\lambda)}$ is the transmittance 
of the atmosphere at the wavelength $\lambda ; \varepsilon_{(\lambda)}$ is the monochromatic emissivity of the object at the wavelength $\lambda$ [12-14].

\section{Materials and Methods}

In order to exploit the above-described mathematical models, it is important to know the transmittance of the covering material in the wavelengths of the visible and long wave infrared. Using these parameters it is possible to evaluate the efficiency of the covering material for the purposes of the greenhouse effect in the structures for protected crops. In this paper we analyze the spectrum of an innovative photovoltaic film created as part of the research project "ECOFLECS" by the Research Unit of Tor Vergata (Rome) for its efficiency in the greenhouse cover.

The film was made in PVB, laminating material that covers the modules at sandwich, plastic substrates PET/ITO, conducting polymer Pedot-PSS. 6 arrays of 8 modules each were realized. The thickness of the flexible film is about $0.5 \mathrm{~mm}$. The single module has the following sizes: $220 \mathrm{~mm} \times 220 \mathrm{~mm}$. These modules can be assembled to obtain large surfaces necessary for the covering of greenhouses. The remarkable flexibility allows the photovoltaic film to fit even to curved surfaces of the tunnels and greenhouses tunnel.

IR measurements were performed with a Perkin Elmer Paragon 1000 instrument with Detector MCT (mercury telluride and cadmium); UV-VIS measurements were performed with a Lambda 9, Perkin Elmer, with photomultiplier highly sensitive at VIS and NIR.

In both cases, the optical filter was set equal to $2[\mathrm{~nm}]$, while the sweep was $120[\mathrm{~nm} / \mathrm{min}]$.

\section{Results and Discussion}

Three samples of semi-transparent films (innovative solutions and still in the experimental phase) were analysed in the spectrophotometer. Diagrams with the average values of the measurements are shown in Figure 2.

Figure 2 shows the trend of the transmittance of the photovoltaic film in relation with the solar spectrum. It seems clear that the transmittance is very low in the first part of the visible, is maintained below $10 \%$ up to 395 [nm], about $38-40 \%$ between 400 and 520 [nm], increases almost linearly up to $650[\mathrm{~nm}]$ where it reaches $68 \%$, and remains almost constant up to $760[\mathrm{~nm}]$.

The average transmittance determined as the arithmetic average is $56.9 \%$ but in this way does not take into account the variation of the flow of solar energy as a function of wavelength (solar spectral irradiance at sea level).

More precisely, the determination of the average transmittance with the weighted average using the flow of solar radiation at different wavelengths is

$$
\tau_{m}=\frac{\sum_{\curlywedge=380}^{760}\left(\tau_{\lambda} \cdot \mathrm{SR}_{\curlywedge}\right)}{\sum_{\curlywedge=380}^{760} \mathrm{SR}_{\curlywedge}}
$$

where $\mathrm{SR}_{\curlywedge}$ is the solar radiation at sea level $\left[\mathrm{Wm}^{-2} \mathrm{~nm}^{-1}\right]$ and $\tau_{\lambda}$ is the photovoltaic film transmissivity [\%]. In this way the average transmittance of the photovoltaic film in the range $380-760[\mathrm{~nm}]$ is equal to $49.5 \%$, value less than that obtained by measuring with a 


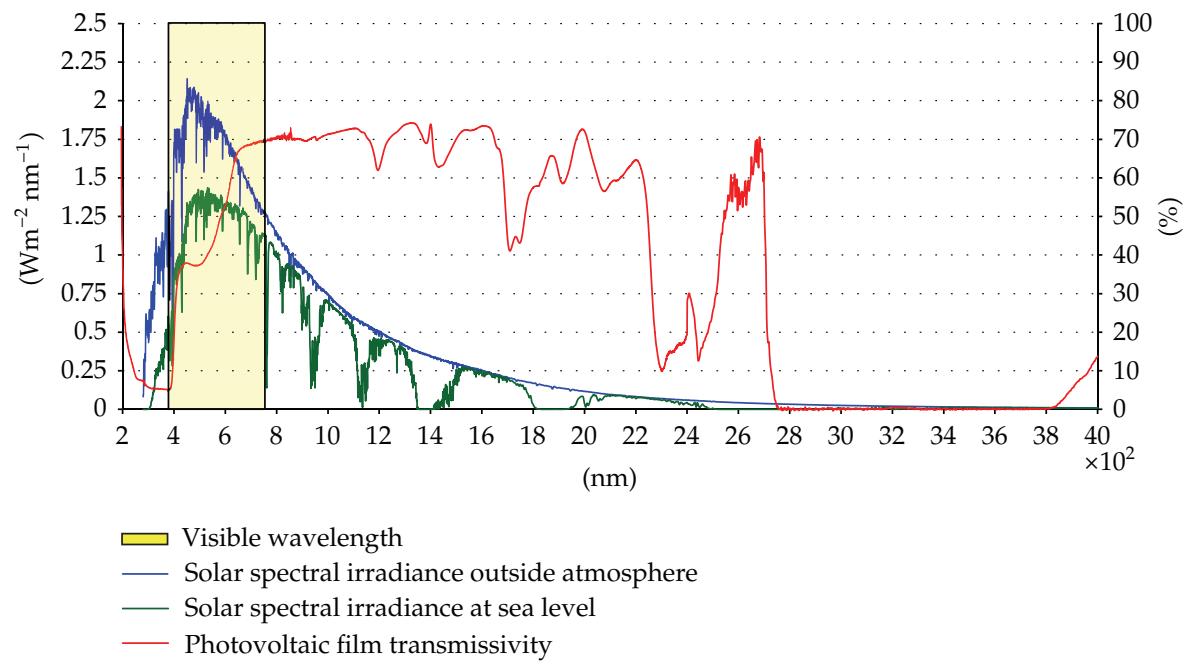

Figure 2: Solar spectral irradiance outside atmosphere and at sea level and photovoltaic film transmissivity in the wavelength range $200-4000$ [nm].

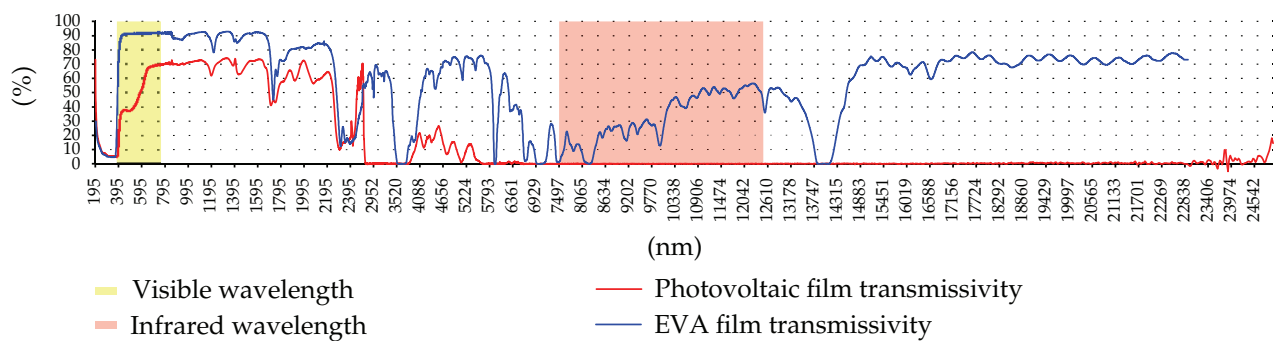

Figure 3: Photovoltaic film transmissivity and EVA film transmissivity in the wavelength range 195-25000 $[\mathrm{nm}]$.

pyranometer solar radiation above and below the photovoltaic film in the range of 300$1100[\mathrm{~nm}]$ but comparable to it because in the near infrared the energy is lower in respect to visible.

For the photovoltaic effect the useful wavelength is between 400 and 1100 [nm], and then the low transmittance before $650[\mathrm{~nm}]$ is advantageous for the production of electricity.

Figure 3 shows the transmissivity of the photovoltaic films and that of the EVA films which are very common in the greenhouse covering. Furthermore, the wavelengths of visible (380-760 [nm]) and long wave infrared (7500-12500 [nm]) were also highlighted since they are important for the purposes of the greenhouse effect.

The indoor greenhouse air temperature rises with the decrease of the long wave infrared transmissivity coefficient of the greenhouse covering material.

High transmissivity in the visible and low transmissivity in long wave infrared are essential to a good greenhouse effect.

The transmissivity in the visible of photovoltaic films, as reported above, is very low up to $650[\mathrm{~nm}]$. As a matter of fact, the average value in the visible is less than $50 \%$ while that 


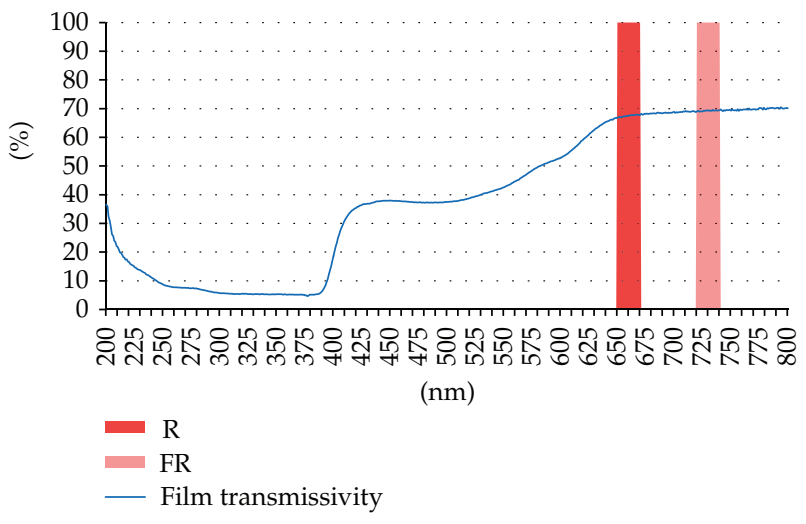

Figure 4: Total transmissivity of the photovoltaic film with red (R, 650-670 [nm]) and far-red (FR, 720$740[\mathrm{~nm}])$ wavelengths in the range $200-800[\mathrm{~nm}]$.

of the EVA film is of about $90 \%$, much higher value. If the photovoltaic film loses a lot in the visible, it gains a lot in the far infrared: its transmittance is practically null in this range of wavelengths that, as it is known, is the interval where it is greater than the energy emitted by radiation from the bodies (Planck's law). Thus, from our point of view, it seems reasonable to assume an overall efficiency of the photovoltaic film in the greenhouse effect similar to that of traditional EVA films.

Figure 4 shows the transmissivity of the photovoltaic film in the range $200-800$ $[\mathrm{nm}]$, pointing out the values of the red $(\mathrm{R}, 650-670[\mathrm{~nm}])$ and far-red (FR, 720-740 $[\mathrm{nm}])$ wavelengths. The ratio between these values is important for the purposes of plants, accretion. The calculated ratio is 0.97 for this PV films: this value should encourage increases of the growth and the elongation of shoots.

In relation to the reflectivity and the absorbance this film gives priority to absorbance because absorbed energy is used for the production of electricity with an efficiency that in the current state does not exceed $10 \%$.

\section{Conclusions}

In this paper, the spectrum of an innovative photovoltaic film has been analysed in order to evaluate its efficiency in the greenhouse cover.

Spectral analysis showed that the transmittance of the photovoltaic film is very low in the first part of the visible in relation with the transmittance of the traditional EVA film commonly used for covering greenhouses. This is advantageous for electricity generation, but at the same time is in contrast with the production of plant material since this portion of the spectrum is useful for photosynthesis (PAR).

The transmittance of the photovoltaic film in the range of the infrared long is null, and therefore much lower than that related to the EVA films with considerable advantages for the purposes of achieving the greenhouse effect.

According to this analysis, in the greenhouse effect it is possible to assume an overall efficiency of the photovoltaic film similar to that of the traditional EVA films. 


\section{Nomenclature}

\section{Alphabetic Symbols}

$R$ : Global solar radiation $\left[\mathrm{MJ} \mathrm{m}^{-2} \mathrm{~d}^{-1}\right]$

$R T$ : Energy lost by radiation $\left[\mathrm{MJ} \mathrm{m}^{-2} \mathrm{~d}^{-1}\right]$

C: Energy exchanged by convection $\left[\mathrm{MJ} \mathrm{m}^{-2} \mathrm{~d}^{-1}\right]$

$T$ : Energy lost by transmission $\left[\mathrm{MJ} \mathrm{m}^{-2} \mathrm{~d}^{-1}\right]$

$V$ : Energy lost by ventilation $\left[\mathrm{MJ} \mathrm{m}^{-2} \mathrm{~d}^{-1}\right]$

TR: Plant transpiration $\left[\mathrm{MJ} \mathrm{m}^{-2} \mathrm{~d}^{-1}\right]$

$S$ : Energy transferred by conduction in the deep layers $\left[\mathrm{MJ} \mathrm{m}^{-2} \mathrm{~d}^{-1}\right.$ ]

E: Thermal storage $\left[\mathrm{MJ} \mathrm{m}^{-2} \mathrm{~d}^{-1}\right]$.

\section{Subscripts}

$\begin{array}{ll}e: & \text { External } \\ \text { re: } & \text { Reflected external } \\ \text { ac: } & \text { Absorbed by the cover } \\ i: & \text { Internal } \\ \text { ri: } & \text { Reflected internal } \\ \text { ap: } & \text { Absorbed by the plants } \\ \text { rg: } & \text { Reflected from the ground } \\ \text { ag: Absorbed by the soil } \\ c: & \text { Covering film } \\ p: & \text { Plants } \\ g: & \text { Ground } \\ \text { ia : } & \text { Indoor air } \\ \text { oa: } & \text { Outdoor air } \\ \text { atm: Atmosphere } \\ \text { sky: Vault of heaven. }\end{array}$

\section{References}

[1] A. Mistriotis, C. Arcidiacono, P. Picuno, G. P. A. Bot, and G. Scarascia-Mugnozza, "Computational analysis of ventilation in greenhouses at zero- and low-wind-speeds," Agricultural and Forest Meteorology, vol. 88, no. 1-4, pp. 121-135, 1997.

[2] J. A. Duffie and W. A. Beckman, Solar Engineering of Thermal Processes, John Wiley \& Sons, New York, NY, USA, 1991.

[3] R. Siegel and J. R. Howell, Thermal Radiation Heat Transfer, McGraw-Hill, New York, NY, USA, 1972.

[4] G. Vox, M. Teitel, A. Pardossi, A. Minuto, F. Tinivella, and E. Schettini, Chapter 1: Sustainable Greenhouse Systems, Sustainable Agriculture: Technology, Planning and Management, Nova Science Publishers, New York, NY, USA, 2010.

[5] M. Carlini, T. Honorati, and S. Castellucci, "Photovoltaic greenhouses: comparison ofoptical and thermal behaviour for energy savings," Mathematical Problems in Engineering, vol. 2012, Article ID 743764, 10 pages, 2012.

[6] C. Kittas and A. Bailie, "Determination of the spectral properties of several greenhouse cover materials and evaluation of specific parameters related to plant response," Journal of Agricultural Engineering Research, vol. 71, no. 2, pp. 193-202, 1998. 
[7] C. Kittas, A. Baille, and P. Giaglaras, "Influence of covering material and shading on the spectral distribution of light in greenhouses," Journal of Agricultural Engineering Research, vol. 73, no. 4, pp. 341-351, 1999.

[8] K. Murakami, H. Cui, M. Kiyota, Y. Takemura, R. Oi, and I. Aiga, “Covering materials to control plant growth by modifying the spectral balance of daylight," Plasticulture, vol. 110, no. 2, pp. 2-14, 1996.

[9] H. Smith, "Light quality, photoperception, and plant strategy," Annual Review of Plant Physiology, vol. 33, pp. 481-518, 1982

[10] M. Oren-Shamir, E. E. Gussakovsky, E. Shpiegel et al., "Coloured shade nets can improve the yield and quality of green decorative branches of Pittosporum variegatum," Journal of Horticultural Science and Biotechnology, vol. 76, no. 3, pp. 353-361, 2001.

[11] M. Takaichi, H. Shimaji, and T. Higashide, "Effect of red/far-red photon flux ratio of solar radiation on growth of fruit vegetable seedlings," ActaHorticulturae, vol. 514, pp. 147-156, 2000.

[12] E. Campiglia, G. Colla, R. Mancinelli, Y. Rouphael, and A. Marucci, "Energy balance of intensive vegetable cropping systems in central Italy," Acta Horticulturae, vol. 747, pp. 185-191, 2007.

[13] A. Marucci, E. Campiglia, G. Colla, and B. Pagniello, "Environmental impact of fertilization and pesticide application in vegetable cropping systems under greenhouse and open field conditions," Journal of Food, Agriculture and Environment, vol. 9, no. 3-4, pp. 840-846, 2011.

[14] A. Marucci and B. Pagniello, "Simulation of the growth and the production of the tomato in typical greenhouses of the Mediterranean environment," Journal of Food, Agriculture and Environment, vol. 9, no. 3-4, pp. 407-411, 2011. 


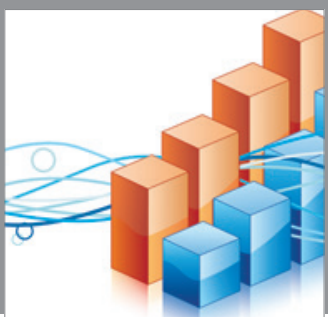

Advances in

Operations Research

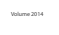

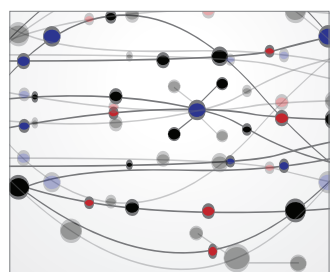

\section{The Scientific} World Journal
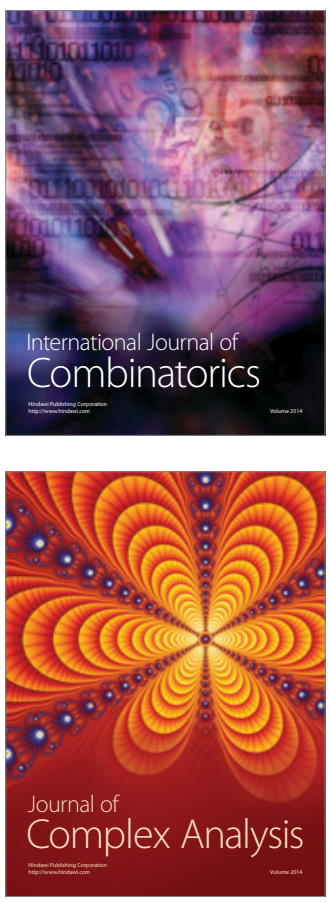

International Journal of

Mathematics and

Mathematical

Sciences
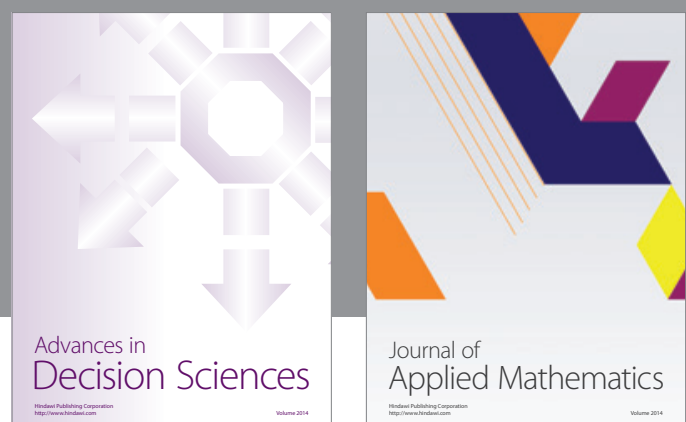

Journal of

Applied Mathematics
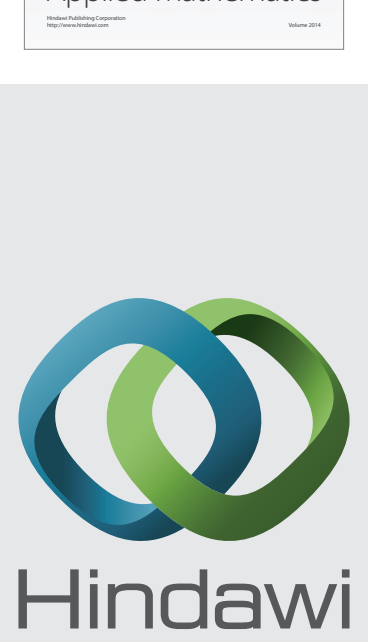

Submit your manuscripts at http://www.hindawi.com
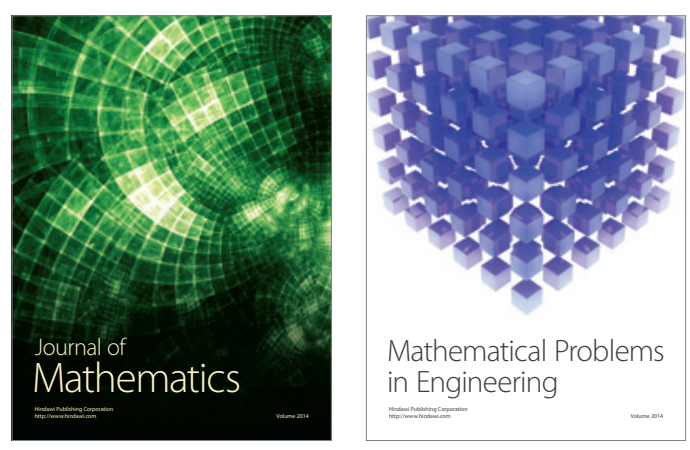

Mathematical Problems in Engineering
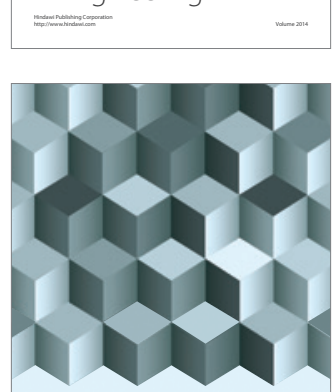

Journal of

Function Spaces
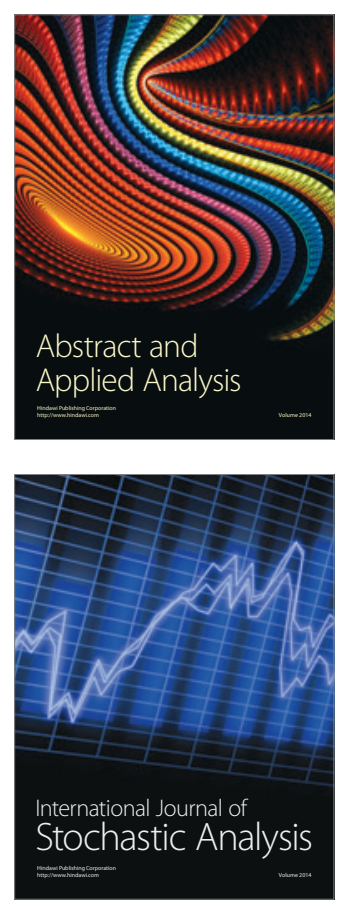

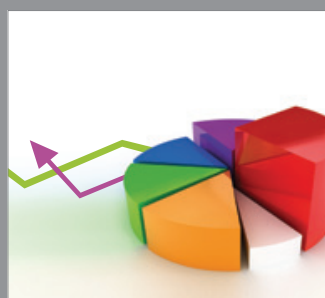

ournal of

Probability and Statistics

Promensencen
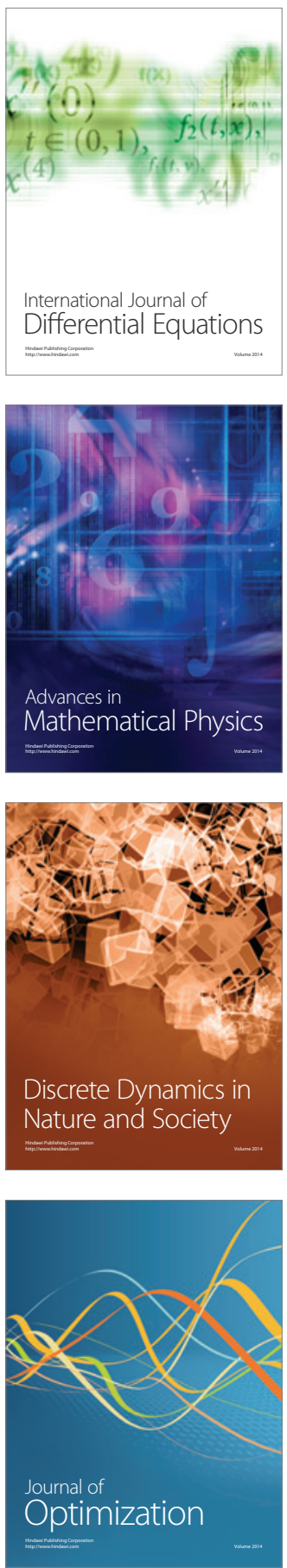